\title{
POLITRAUMA DURING COVID-19 PANDEMIC: AN INCREASING INCIDENCE OF DOMESTIC VIOLENCE
}

B. Socea ${ }^{1,2}$, Cristiana Bogaciu ${ }^{2}$, Anca A. Nica ${ }^{1,2}$, A.C. Smaranda 2 , V.P. Ciobotaru ${ }^{1,2}$, Roxana I. Crăciun ${ }^{2}$, A.C. Carâp ${ }^{1,2}$, I. Slavu ${ }^{1,3}$, A. Tulin ${ }^{1,4}$, L. Alecu ${ }^{1,4}$, C.D. Badiu, ${ }^{1,5}$, V.D. Constantin ${ }^{1,2}$

${ }^{1}$ Carol Davila University of Medicine and Pharmacy, Bucharest, Romania

2 "Sf. Pantelimon" Emergency Clinical Hospital, Bucharest, Department of Surgery

3“"Floreasca" Emergency Clinical Hospital, Bucharest, Romania

4"Prof. Dr. Agrippa Ionescu" Emergency Clinical Hospital, Bucharest, Romania

5"Bagdasar-Arseni" Emergency Clinical Hospital, Bucharest, Romania

\begin{tabular}{c} 
ORIGINAL \\
PAPER \\
\hline
\end{tabular}

DOI: $10.33695 /$ rojes.v2i1.20

Accepted: 13.04.2020

\section{Abstract}

The Covid-19 pandemic changed certain social habits and practices. The pandemic also changed the profile of polytrauma patients who presented in the emergency room. The etiology of polytraumas has undergone changes in the context of social distancing. While road accidents, falls and physical assaults, including gunshot trauma on the streets have decreased, we are confronting with an alarming increase in domestic violence. We analyzed the etiology of polytraumas from a period of 3 months that overlapped with the pandemic and compared it with the similar periods of the previous 3 years. We found an increase of about 4 times the incidence of physical aggression through domestic violence.

Corresponding author: Bogdan Socea bogdan.socea@umfcd.ro

Keywords: polytrauma, domestic violence, Covid-19, pandemic

\section{Introduction}

Interpersonal, domestic and intimate partner violence are important public health problems worldwide. This type of trauma can lead to long-term physical and mental consequences for the victims [1,2].

The World Health Organization (WHO) defines domestic violence as "behavior by a partner that causes physical, sexual, or psychological harm, including acts of physical aggression, sexual coercion, psychological abuse, and controlling behaviors" $[3,4]$.

There are reported cases of domestic violence in heterosexual as in same-sex relationships and they do not have necessary a sexual component $[5,6]$.

One type of domestic violence is intimate partner violence and the Center for Disease Control and Prevention defines it as "a person with whom one has a close personal relationship that can be characterized by the following: emotional connectedness, regular contact, ongoing physical contact and/or sexual behavior, identity as a couple, or familiarity and knowledge about each other's lives" [7].

Organizations such as American College of Surgeons and the WHO report domestic violence as a major public health issue [8]. 
The Centers for Disease Control in 2010 estimated that $24.3 \%$ (or 1 in 4 ) women and $13.8 \%$ ( 1 in 7 ) men have experienced severe physical violence from an intimate partner in their lifetimes. Intimate partner violence may lead to a whole host of physical, emotional and cognitive impairments, including traumatic brain injury which is often less visible than other forms of intimate partner violence-related injuries (e.g. bruises or broken bones), these injuries may go undetected and untreated despite symptoms that may last for days or months following the injury [9-11].

Intimate partner violence describes "any form of physical, sexual, emotional, psychological, and/or verbal abuse between partners in an (current or former) intimate relationship" [12]. The European Union implemented a survey about violence against women and the results are intriguing for a modern and developed wanna-be society. They interviewed 42.000 women from 28 European states. The most terrifying result is that 1 in 3 women has experienced physical and/or sexual violence (at least once since she was 15). $22 \%$ of women have physical or sexual violence by a partner and $11 \%$ of women have experienced some form of sexual violence.

Another hard-to-swallow truth is that 1 in 2 women has been sexually harassed and $5 \%$ have been raped. The most frequent emotional response to sexual violence are anger, fear, shame, guilt, and embarrassment.

There are some types of psychological violence such as: controlling behavior (trying to keep a woman from seeing friends, family or relatives; jealousy beyond normal concern); economic violence (preventing a woman from making decisions on family finances or shopping independently; forbidding her to work outside the home); abusive behavior (forbidding a woman to leave the house or locking her up; scaring or intimidating her on purpose; threatening her with violence or threatening to hurt someone else the respondent cares about); blackmail with/abuse of children [13].

There are some ways of helping the victims such as proactively assist and address unwanted behavior through social media platforms, specialist training and adequate resources for support organizations, healthcare, employers, police and review and implementation of existing laws and policies.

During the Covid-19 pandemic, a decrease in the incidence of polytraumas through car accidents, firearms and falls was observed in the most affected countries, the explanation being social distancing $[14,15]$.

\section{Materials and method}

The coronavirus epidemic broke out in Wuhan, China, in a Metropolis of 11 million people in December 2019 [16]. Free movement of people led to the spread of the virus in Europe (Italy), the United Kingdom and the United States in January-February 2020, becoming soon a pandemic that affected almost all countries [17,18]. In our country, the first positive confirmed patient infected with SARS-CoV-2 was on 26th of February 2020, and from 16th of March, the authorities declared the urgency state.

We analyzed all the polytrauma patients presented and admitted in our Surgical Department in a 3 months period (from 16th of March to 15th of June 2020) and we compared the results with those of the similar periods of the previous 3 years (16th of March - 15th of June 2017, 16th of March 15th of June 2018 and respectively 16th of March - 15th of June 2019).

Our study was a retrospectively descriptive study, the data being collected from the emergency registries.

\section{Results and Discussions}

In the period 15th of March - 15th of June 2020, there were 168 patients admitted in our Clinic for polytraumas. Sex ratio was 
of 1.5:1 (M:F), medium age of 43.2 years (extremes 18 , respectively 78 years of age, standard deviation 4.3).

The compared number of polytrauma cases from similar periods of the previous years from our Department can be found in table 1 . We can see that the global number of patients with polytrauma admitted in surgical department was lower in a pandemic period of three months, compared with a similar period from three previous years.

\begin{tabular}{|c|c|c|c|c|}
\hline Year & $\mathbf{2 0 1 7}$ & $\mathbf{2 0 1 8}$ & $\mathbf{2 0 1 9}$ & $\mathbf{2 0 2 0}$ \\
\hline $\begin{array}{c}\text { Number of } \\
\text { patients with } \\
\text { polytrauma }\end{array}$ & 171 & 179 & 185 & 168 \\
\hline
\end{tabular}

Table 1 - Number of patients with polytrauma admitted in the same period of four consecutive years (between 16th of March and 15th of June)

Comparing the demographics characteristics of the four cohorts, they proved to be quite similar regarding medium and extreme ages, sex ratio, medium of their provenience - urban versus countryside.

The etiology of polytrauma is comparatively presented in table 2 .

\begin{tabular}{|c|c|c|c|c|}
\hline Etiology/Year & $\mathbf{2 0 1 7}$ & $\mathbf{2 0 1 8}$ & $\mathbf{2 0 1 9}$ & $\mathbf{2 0 2 0}$ \\
\hline $\begin{array}{c}\text { Car/motorcycle/ } \\
\text { bicycle accidents }\end{array}$ & 54 & 59 & 62 & 37 \\
\hline Falls & 45 & 42 & 47 & 38 \\
\hline $\begin{array}{c}\text { Street } \\
\text { aggressions }\end{array}$ & 42 & 45 & 51 & 38 \\
\hline $\begin{array}{c}\text { Domestic } \\
\text { violence }\end{array}$ & 7 & 8 & 9 & 34 \\
\hline Other & 23 & 25 & 16 & 21 \\
\hline Total & $\mathbf{1 7 1}$ & $\mathbf{1 7 9}$ & $\mathbf{1 8 5}$ & $\mathbf{1 6 8}$ \\
\hline
\end{tabular}

Table 2 - Etiology of trauma related to last years

In addition to the decrease in frequent etiologies of trauma, but without statistical significance, this year there is a significant increase in cases of domestic violence. The victims of domestic violence during pandemic times were all women, aged between 31 and
74 years (medium age 48.2). The lesions were, in most cases, not severe, the patients requiring only medical supervision in 27 from 34 cases $(79.4 \%)$. The spectrum of lesions encountered consisted of contusions, hematomas, rib fractures, craniocerebral trauma with viscerocranial damage and mono/biocular damage, clavicle fractures, articular dislocations, two cases of hemo/pneumothorax that needed drainage, hemoperitoneum through splenic ruptures (3 cases) and grade 1-2 liver lacerations (2 cases) that required surgery.

Regarding the cases of domestic violence, they were $4.85,4.25$ and respectively 3.77 times (on average 4.3) more numerous than in the non-pandemic period: similar periods of years 2017, 2018 and respectively 2019, with statistical significance $(\mathrm{p}<0.05$ - chi square test). Correcting the number of cases with the total number of traumas, we obtain even greater differences in percentages in which domestic violence constituted the etiology of polytraumas in Covid-19 pandemic: $20.23 \%$ compared to $4.09 \%$ (2017), $4.47 \%$ (2018) and $4.86 \%$ (2019).

Our data are in line with similar data from the literature, on an increase in the proportion of domestic aggression in polytraumas during pandemic times.

Some studies in China and UK have revealed depression and anxiety due to the COVID-19 outbreak $[19,20,21]$. The pandemic has led to numerous cases of depression and anxiety, as well as worsening pre-existing mental illnesses [22]. Quarantine, isolation and spending many hours in the company of the same people (even family members) has led, in some cases, to exacerbation of aggression and increased violence. Stress, loss of income and isolation, all can exacerbate the risk of violence at home during pandemics.

The young age of women that suffered aggressions in our study correspond with data from the literature. It is known that younger women are more often assaulted by their 
partners. As women become older, the risk of domestic violence decreases [23].

All studies concerning domestic violence in Romania show that women are more affected than men. Women are more likely to be injured in attacks, to have been subject to frightening threats, to have suffered multiple assaults and to have been upset and frightened at the time of the incident [24]. And this is not only a specific profile for our country. In Austria, for example, in nine in ten cases, victims of domestic violence were female [25].

\section{Conclusions}

The data show that our country is part of the global trend of reorientation of the causes of polytrauma in pandemic context, with the decrease of road accidents, falls, physical street aggressions and firearms, in exchange for the increase of traumas produced by domestic violence. All our cases, victims of domestic violence in a period of three month of covid-19 pandemics were women. We found an increase in the percentage of polytraumas due to domestic violence about 4 times, compared to similar periods in previous years, without a pandemic context.

\section{References}

[1] Tennakoon, L., Hakes, N. A., Knowlton, L. M., Spain, D. A., Traumatic Injuries Due to Interpersonal and Domestic Violence in the United States. Journal of Surgical Research. 2020; 254:206-216. doi: 10.1016/j.jss.2020.03.062

[2] Alsaker K, Moen BE, Morken T, et al. Intimate partner violence associated with low quality of life a cross-sectional study. BMC Womens Health. 2018;18:1e7.

[3] Stewart DE, Vigod SN. Update on mental health aspects ofintimate partner violence. Med ClinNorth Am. 2019;103:735e749.

[4] Boyle A, Robinson S, Atkinson P. Domestic violence inemergency medicine patients. Emerg Med J. 2004;21:9e13.
[5] Sugg N. Intimate partner violence: prevalence, healthconsequences, and intervention. Med Clin North Am. 2015;99:629e649.

[6] Dicola D, Spaar E. Intimate partner violence. Am Fam Physician. 2016;94:646e651.

[7] Chisholm CA, Bullock L, Ferguson JE. Intimate partnerviolence and pregnancy: epidemiology and impact. Am J Obstet Gynecol. 2017;217:141e144.

[8] DeBoer MI, Kothari R, Kothari C, et al. What are barriers tonurses screening for intimate partner violence? J TraumaNurs. 2013;20:155e160.

[9] Tjaden P, Thoennes N. Full report of the prevalence, incidence, and consequences of violence against women: Findings from the national violence against women survey (NIJ publication No. 183781). 2000. Washington, DC: U.S. Department of Justice, National Institute of Justice.

[10] Ellsberg M, Jansen H, Heise L, Watts $\mathrm{CH}$, Garcia-Moreno C. Intimate partner violence and women's physical and mental health in the WHO multi-countrystudy on women's health and domestic violence: An observational study. The Lancet. 2008;371:1165-1172. doi:10.1016/S01406736(08)60522-X

[11] Plichta SB. Intimate partner violence and physical health consequences: Policy andpractice implications. Journal of Interpersonal Violence. 2004;19:1296-1323. doi:10.1177/ 0886260504269685

[12] Murray CE, Graves KN. Responding to family violence. 2012. New York, NY: Routledge.

[13] Nevala S. Violence against women: an EU-wide survey. https://rm.coe.int/1680591fd9

[14] Aljuboori Z, Sieg E. The early effects of social distancing resultant from COVID-19 on admissions to a Level I trauma center [published online ahead of print, 2020 Jun 25]. Injury. 2020;S0020-1383(20)30543-X. doi:10.1016/j.injury.2020.06.036 
[15] Caputi TL, Ayers JW, Dredze M, Suplina N, Burd-Sharps S. Collateral Crises of Gun Preparation and the COVID-19 Pandemic: Infodemiology Study. JMIR Public Health Surveill. 2020;6(2):e19369. Published 2020 May 28. doi:10.2196/19369 [16] Tang JW, Tambyah PA, Hui DSC. Emergence of a novel coronavirus causing respiratory illness from Wuhan, China. J. Infect. 2020;80:350-371.

[17] Arshad AS, Baloch M, Ahmed N, Arshad AA, Iqbal A. The outbreak of Coronavirus Disease 2019 (COVID-19)-An emerging global health threat. J. Infect. Public Health. 2020.

[18] Dimitriu MCT, Pantea-Stoian A, Smaranda AC, et al. Burnout syndrome in Romanian medical residents in time of the COVID-19 pandemic [published online ahead of print, 2020 Jun 7]. Med Hypotheses. 2020;144:109972.

doi:10.1016/j.mehy.2020.109972

[19] Chen Q, Liang M, Li Y, et al. Mental health care for medical staff in China during the COVID-19 outbreak. Lancet Psychiatry. 2020;7:e15-e16.
[20] Koh D. Occupational risks for COVID19 infection. Occup Med (Lond). 2020;70:35.

[21] Rimmer A. Covid-19: give NHS staff rest spaces and free parking not thank yous, says doctor. BMJ. 2020;368:m1171.

[22] Lai J, Ma S, Wang Y, et al. Factors associated with mental health outcomes among health care workers exposed to Coronavirus Disease 2019. JAMA Netw Open. 2020;3:e203976.

[23] Lamplot E. Domestic Violence in Romanian Society, SIAK-Journal Zeitschrift für Polizeiwissenschaft und polizeiliche Praxis. 2009; 3: 40-48, doi: 10.7396/2009_3_F.

[24] Walby S, Myhill A. Policing \& Reducing Crime. Reducing domestic violence - What works? Briefing Notes, University of Leeds, 2000.

[25] Haller B, Pelikan C, Smutny P. The Austrian Protection against Domestic Violence. Act 1996, Crime Policy in Europe, Council of Europe Publishing, 2006; 37-46. 